Société d'histoire de la révolution de 1848 et des

révolutions du XIXe siècle

$61 \mid 2020$

Dans l'intimité de l'exil

Michèle HANNOOSH, Jules Michelet. Writing Art and History in Nineteenth-Century France

\title{
Paule Petitier
}

\section{OpenEdition \\ Journals}

Édition électronique

URL : https://journals.openedition.org/rh19/7290

DOI : $10.4000 /$ rh 19.7290

ISSN : $1777-5329$

Éditeur

La Société de 1848

Édition imprimée

Date de publication : 1 décembre 2020

Pagination : 284-286

ISSN : 1265-1354

Référence électronique

Paule Petitier, « Michèle HANNOOSH, Jules Michelet. Writing Art and History in Nineteenth-Century

France ", Revue d'histoire du XIXe siècle [En ligne], 61 | 2020, mis en ligne le 20 janvier 2021, consulté le

20 août 2021. URL : http://journals.openedition.org/rh19/7290 ; DOl : https://doi.org/10.4000/

rh19.7290

Ce document a été généré automatiquement le 20 août 2021.

Tous droits réservés 


\title{
Michèle HANNOOSH, Jules Michelet. Writing Art and History in Nineteenth- Century France
}

\author{
Paule Petitier
}

\section{RÉFÉRENCE}

Michèle HANNOOSH, Jules Michelet. Writing Art and History in Nineteenth-Century France, University Park, The Pennsylvania State University Press, 2019, 231 p., 94,95 \$.

1 L'intérêt de Michelet pour les arts a fréquemment sollicité l'attention de la critique, de Jean Pommier à Pierre Malandain, de Roland Barthes à Chakè Matossian (auteur de Fils d'Arachné. Les Tableaux de Michelet en 1998). Michèle Hannoosh rouvre librement le dossier pour développer dans son essai l'hypothèse selon laquelle la pensée historique de Michelet trouverait sa source dans une méditation sur les arts plastiques. L'essai est relativement bref, largement nourri de citations de l'historien, illustré de reproductions de grande qualité bien qu'en noir et blanc. Il s'appuie tant sur la lecture de l'Histoire de France que sur celle du Journal et des Cours, ces derniers constituant non seulement une source de considérations supplémentaires sur l'art mais aussi un moyen de mettre en perspective ces propos en s'appuyant sur la genèse des œuvres et l'évolution intellectuelle de l'auteur.

2 M. Hannoosh commence par étayer solidement sa proposition de lecture en rapprochant Michelet de Michel Foucault et de Michel de Certeau qui, au xx $x^{e}$ siècle, ont l'un et l'autre intégré à des ouvrages majeurs des analyses d'œuvres picturales emblématiques de leur méthode et de leurs conceptions (Les Ménines de Vélasquez au début des Mots et les Choses; une gravure de Théodore Galle dans l'« Avant-Propos » de L'Écriture de l'histoire). Exposant fort clairement dans son premier chapitre les démarches des deux penseurs $d u x^{e}$ siècle, $M$. Hannoosh considère qu'elles viennent 
étayer l'hypothèse d'un rôle comparable chez leur prédécesseur du xix siècle, dont elle suggère même qu'il pourrait être à l'origine de ce procédé (p. 26).

Les développements qui suivent s'organisent en quatre chapitres centrés sur des périodes : le Moyen Âge, la Renaissance, les guerres de Religion et enfin la Révolution et le début $d u X_{X X}^{e}$ siècle. La conclusion réaffirme le parallèle entre histoire et peinture à partir des commentaires écrits par Michelet sur Rembrandt. Il s'agit à chaque fois de montrer que l'intérêt de Michelet pour l'art de la période en question a eu un rôle séminal dans sa pensée et a nourri l'élaboration de catégories historiques neuves. Les prémisses de l'interprétation reposent sur le fait que Michelet conçoit le rapport au passé sur le mode du dialogue, d'une interaction à la faveur de laquelle l'un et l'autre s'interrogent. Selon M. Hannoosh, c'est de là que provient la place éminente de l'art dans la réflexion historique : en effet, fortement enracinée dans un moment du passé dont elle est en partie l'expression, l'œuvre d'art traverse les siècles sans disparaître (contrairement au passé lui-même), et porte ainsi jusqu'à nous la présence de ce temps évanoui, par conséquent la possibilité de tisser avec une lui une relation vivante. M. Hannoosh exprime fort bien cette thèse et son style délié et enthousiaste fait qu'on la suit avec grand intérêt dans son raisonnement. Après quoi, Moyen Âge, Renaissance, guerres de Religion et période révolutionnaire constituent les cas successifs sur lesquels tester la grille de lecture ainsi posée.

4 À propos de l'art gothique, M. Hannoosh suit les variations de la vision michelettiste du Moyen Âge, et assigne au tournant des années 1840, non une cause politique comme on le fait habituellement, mais un motif esthétique: lors de visites des cathédrales de Reims et de Strasbourg, Michelet aurait été frappé par ce qui s'y laissait voir de l'oppression du peuple et aurait ainsi été amené à réviser son appréciation du début des années 1830, qui, elle-même, souligne M. Hannoosh, n'était pas sans contenir les germes d'un possible retournement. De même pour ce qui est de la Renaissance : les événements de 1848-1852 passent à l'arrière-plan causal, tandis que les visites de l'historien aux musées de Belgique, de Hollande et d'Allemagne dans les années 1840 sont considérées comme déterminantes. La passion de Michelet pour le château de Fontainebleau et son admiration pour des artistes comme Jean Goujon ou Germain Pilon l'ont rendu éminemment sensible au drame des guerres de Religion, tandis que sa scrutation intense de l'œuvre de Géricault le poussait à envisager les contradictions internes des notions de " peuple » et de « nation » à l'époque où il écrivait. Par bien des aspects - et notamment par la vivacité de l'écriture - l'essai de M. Hannoosh provoque l'adhésion du lecteur, qui redécouvre sous un éclairage partiellement inattendu l'univers intellectuel et esthétique de Michelet, avec ses idées-forces et ses interrogations fondamentales.

5 Peut-on cependant suivre la proposition de lecture dans sa radicalité, et admettre que la pensée de Michelet serait en première instance tributaire de son rapport vivant et charnel avec les œuvres d'art? Celles-ci comptent sans doute pour beaucoup, mais nous doutons qu'elles relèguent au second plan les interactions avec les événements contemporains et leurs répercussions sur la vie et les conceptions socio-politiques de Michelet. Par ailleurs, même si nous savons bien qu'un essai est un essai, et qu'il perdrait à vouloir tout embrasser, nous nous demandons s'il fallait en écarter aussi complètement toute référence à la critique et à l'histoire de l'art au XIXe siècle. Michelet n'est pas le seul à écrire sur les arts plastiques en son temps et il aurait été intéressant de mesurer en quoi son discours ressemble à celui qui est en train de s'élaborer chez 
d'autres auteurs, en quoi il en diffère. Enfin, pourquoi certains pans de l'œuvre sont-ils absents? Les tomes de l'Histoire de France qui suivent le récit des guerres de Religion contiennent beaucoup de références à l'art (commentées d'ailleurs dans un long article de Pierre Malandain). Le rapport de Michelet aux portraits n'est pas du tout abordé, alors que son observation des tableaux sert pratiquement toujours de point de départ aux évocations imagées des acteurs de l'histoire - il ne cesse d'en être question entre autres dans l'Histoire de la Révolution.

6 L'essai de Michèle Hannoosh, alerte et convaincant, offre une entrée attrayante dans l'œuvre foisonnante de Michelet. Par ses nombreux extraits traduits en anglais, par son large angle de vue, par ses commentaires qui font ressortir l'art d'écrire de l'historien, il jouera, nous l'espérons, un rôle incitatif pour renforcer les études anglophones sur cet auteur. 